\title{
Communicating climate change - Learning from business: challenging values, changing economic thinking, innovating the low carbon economy
}

\author{
KATHARINA KAESEHAGE, MICHAEL LEYSHON AND CHRIS CASELDINE
}

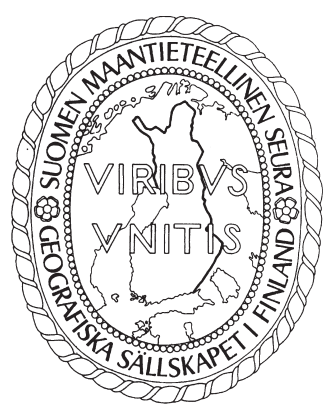

Kaesehage, Katharina, Michael Leyshon \& Chris Caseldine (2014). Communicating climate change - Learning from business: challenging values, changing economic thinking, innovating the low carbon economy. Fennia 192: 2, pp. 81-99. ISSN 1798-5617.

The risks and opportunities presented by climate change for Small and Medium Sized Enterprises (SMEs) have been largely overlooked by previous research. The subsequent lack of knowledge in this field makes it difficult for SMEs to engage with climate change in a meaningful, profitable, and sustainable way. Further, current research cannot explain why SMEs rarely engage with climate change. We examine critically 30 SMEs, which engage with climate change knowledges and 5 Innovation-Support-Organizations (ISOs) that communicate climate change knowledges. Over a three-year period we explore why and how these businesses approach the knowledge gap between climate change science and business practice, drawing on a variety of ethnographic research methods: (1) in-depth semi-structured and open interviews; (2) participant observations; and (3) practitioners' workshops. The results demonstrate that business' mitigation and adaptation strategies are lay-knowledge-dependent, derived from personal values, space, and place identity. To enhance the number of SMEs engaging with climate change, maximize the potential value of climate change for the economy and establish a low carbon economy, climate change communication needs to target personal values of business leaders. The message should highlight local impacts of climate change, the benefits of engagement to (the local) society and economy, and possible financial benefits for the business. Climate change communication therefore needs to go beyond thinking about potential financial benefits and scientific evidence and challenge values, cultures, and beliefs to stimulate economic, political, and social frameworks that promote values-based decision-making.

Keywords: United Kingdom, climate change, communication of science, business values, low carbon economy, ethnographic research

Katharina Kaesehage, Michael Leyshon \& Chris Caseldine, College of Life and Environmental Sciences, University of Exeter, Treliever Road, Penryn TR10 9EZ, United Kingdom. E-mail: k.kaesehage@exeter.ac.uk

\section{Purpose: learning from businesses}

The risks and opportunities presented by climate change for Small and Medium Sized Enterprises $(\mathrm{SMES})^{1}$ have largely been overlooked by previous research. Questions of how to communicate climate knowledge to SMEs have remained unanswered and consequently make it difficult for SMEs to engage with climate science in a meaningful, profitable, and sustainable way (cf. Goodall
2008). Contemporary research exploring the relationship between SMEs and climate change is very limited and does not adequately explain how businesses understand and interpret climate issues (cf. Hoffman 2004, 2006; Hart 2007, Williams \& Schaefer 2013). The purpose of this paper therefore is to redress this imbalance by studying how business leaders of SMEs understand climate change and make climate change relevant to their individual decision-making. Although it is difficult 
to draw a definite distinction between intended and actual engagement as well as between climate change and broader environmental issues, we investigate the intentional engagement of business leaders with climate change only (cf. Corner et al. 2014). The study therefore investigates SMEs across sectors that are prepared to engage with the risks and potentials of climate change. This is an important approach because a lack of innovation is often a result of looking too much to organizations that are wedded to current systems instead of looking to organizations that do things differently (Christensen et al. 2006). Engagement with climate change refers to any behaviour a business associates with climate change and does not distinguish between mitigation and/ or adaptation, as "both synergies and trade-offs exist between adaptation and mitigation options" but neither adaptation nor mitigation alone can prevent climate change related impacts (IPCC 2007: 61). Importantly, this investigation does not seek to evaluate the effectiveness and appropriateness of mitigation and/or adaption actions that individual businesses adopt. Instead, the sole focus is to understand the ways in which business leaders of SMEs make-sense of, and engage with, climate change within their business. To unpick this diverse and individual engagement it is the sense-making of climate change, which shapes and is shaped by the actual engagement (Geoghegan \& Brace 2011), on which this study focuses. We only pay attention to (for-profit) SMEs because they are crucial to mitigate and adapt to climate change and initiate behaviour change among society: $99.9 \%$ of United Kingdom's (UK) 4.9 million private sector businesses are SMEs employing $59 \%$ of the employed population (BIS 2013). Businesses are said to be substantially linked to the UK's total greenhouse gas (GHG) emissions; estimates link up to $50 \%$ of the UK's GHG emissions to businesses (Rajgor \& Malachowsk 2005).

The purpose of this study is to:

(1) Explore how business leaders of SMEs across sectors conceptualize climate change to bring it within the decision-making process.

(2) Discover the factors that trigger business leaders to engage with climate change.

(3) Investigate how these motivations suit the current socio-economic system(s) and influence subsequent decision-making.
We will now outline the climate change and business challenge in respect to the extant literature and then explain the variety of ethnographic research tools we used to explore why and how SMEs approach the knowledge gap between climate change science and business practice. The findings are structured in three sub-sections: firstly, we will demonstrate that climate change is a future issue, which the majority of 'engaged SMEs' have not yet materially been impacted by, making it difficult for business leaders to construct a link between possible future impacts of climate change and current economic activities; secondly, we will show that personal values of participating business leaders trigger engagement with climate change on behalf of their businesses; and thirdly, we will show that climate change is an ethical debate over values and culture (cf. Hoffman 2012), which does not easily fit with current socio-economic and geopolitical systems. We conclude that to enhance the number of SMEs engaging with climate change, maximize the potential value of climate change for the economy and establish a low carbon economy, climate change communication needs to target personal values of business leaders. The message should highlight local impacts of climate change, the benefits of engagement to (the local) society and economy, and possible financial benefits for the business. Climate change communication therefore needs to go beyond thinking about potential financial benefits and scientific evidence and challenge values, cultures, and beliefs to stimulate economic, political, and social frameworks that promote values-based decision-making. Committed business leaders provide a valuable way to address such issues.

\section{The climate change and business challenge}

Even though climate change is primarily a physical phenomenon, most recently defined as "a change in the state of the climate that can be identified ... by changes in the mean and/or the variability of its properties, and that persists for an extended period ....... due to natural internal processes or external forcings" (IPCC 2013: 1450), it is a highly politicised issue that potentially has significant ramifications for the future lives of individuals (Boykoff et al. 2009). Individuals "can't directly sense" climate change (Sarewitz \& Pielke 2000: 56) as it is a 
scientific episteme to express a wide variety of physical processes. The effects of climate change though will have material consequences for human systems (IPCC 2013). Stern (2006: vi) estimates that, based on a variety of formal economic models, "the overall costs and risks of climate change will be equivalent to losing at least 5\%" and up to $20 \%$ "of global GDP each year". The potential impact of climate change on the economy is considered by Porter and Reinhardt (2001: 3) who state:

"Periodically, major new forces dramatically reshape the business world - as globalization and the information technology revolution have been doing for the past several decades. Climate change, in its complexity and potential impact, may rival them both."

Hoffman (2004) suggests these developments will force companies to reassess their overall strategy from capital resources to business culture so that they are in a position to mitigate climate-related costs and risks of "shifting temperature and weather patterns, and ... regulations that increase the cost of emissions" (Porter \& Reinhardt 2007: 3). The social nature of businesses combined with their fiscal resources means they are often better positioned than governments or societies to mitigate and adapt to climate change (Hart 2007). The risks and opportunities posed by climate change to businesses, as well as their responsibilities as major greenhouse gas emitters and potential changemakers, have been a focus of recent research (cf. Reinhardt \& O'Neill Packard 2001; Hoffman 2004; Hart 2007; Porter \& Reinhardt 2007; Patenaude 2011; Koomey 2012). However, businesses rarely concern themselves with these issues (Hart 2007; Goodall 2008; Global Compact 2010; Patenaude 2011).

For example, more than $70 \%$ of global executives do not have emission targets (Enkvist \& Vanthournout 2008) yet a survey by AXA showed that $50 \%$ of businesses view a move towards a low carbon economy as important (Carbon Neutral 2013). These businesses however often fail to take action (Rajgor \& Malachowski 2005). SMEs are estimated to have a greater carbon saving potential than larger businesses, and could collectively save up to 2.5 million tons of $\mathrm{CO} 2$ per year in the UK (Eco-Monitor 2013). Yet many SMEs do not recognize this potential (Carbon Neutral 2013).
Research on business engagement has demonstrated how companies find it difficult to engage with environmental issues (cf. Tilley 1999; Vernon et al. 2003; Jenkins 2006; Revell \& Blackburn 2007; Battisti \& Perry 2011; Cassells \& Lewis 2011). Tilley (1999) for example identified poor eco-literacy and environmental awareness as major obstacles to pro-environmental practices. Parker et al. (2009) as well as Cassells and Lewis (2011) suggest that SMEs are unable to engage with long-term environmental concerns because they have to be present-oriented. Hillary (2004) identified internal barriers, such as resources, understanding, and company culture, as well as external barriers, such as lack of support and guidance, as factors that hinder engagement with environmental issues. A study conducted by Vernon et al. (2003) on the tourism industry in Cornwall showed that small businesses feel that their environmental impact is negligible due to their size (cf. also Cassells \& Lewis 2011; Wilson et al. 2012), indeed SMEs are largely unaffected by environmental regulation (cf. Carter 2007; Visser \& Adey 2007). Additionally, owner-managers of SMEs often pass their environmental responsibility on to the government (Cassells \& Lewis 2011). Revell and Blackburn (2007) and Tilley (1999) describe this as a value-action-gap in which owner-managers of SMEs believe that the environment is important, but choose not to act. Actions around wider Corporate Social Responsibility (CSR) are often associated with individual executives, and their personal values, beliefs, and attitudes (Aragón-Correa et al. 2004; Kerr 2006; Visser \& Crane 2010). These findings are not particularly surprising as shareholder, management, and ownership are closely related in SMEs, and business operations can therefore reflect the characteristics of the owner-manager (Vives 2006). Williams \& Schaefer (2013) most recently showed that managers of SMEs are driven by personal values and beliefs to engage with environmental and climate change related issues. Although SMEs struggle to engage with environmental issues, it is however important to note that it is widely accepted that businesses are dependent on a healthy society, while society is dependent on well-functioning businesses to contribute to a prosperous economy through identifying "the particular set of societal problems that it is best equipped to help resolve and from which it can gain the greatest competitive benefit" (Porter \& Kramer 2006: 14). 
Although the precise reasons for the lack of business engagement with climate change are currently poorly understood, we can infer three general trends in the climate change literature that point to a value-(in)action-gap. First, climate change is a difficult concept to understand, indeed scientific interpretations and terminology are perceived as complex. Climate change knowledges produce time-space temporalities that position the issue as a problem of somewhere else (Geoghegan \& Brace 2011). Second, climate change knowledge is perceived as a political project rather than a scientific discourse and thereby lacks credibility (Hoffman 2012). Finally, business scholars are unaware of the nature and extent of potential climate change (Reinhardt \& O'Neill Packard 2001; Goodall 2008; Patenaude 2011). These broader issues influence business leaders' perceptions of climate change. Conceptualisations of climate change appear to instil an intellectual doubt about the purpose of individual action (Patenaude 2011: $267)$, as timescales of climate change projections are too distant for people to perceive it as an issue of individual importance (Houghton 2009; Geoghegan \& Brace 2011). The void between the impact of an individual's actions and the issue of climate change can invoke feelings of being overwhelmed and helpless (Norgaard 2003). To resolve this, Curtis and Schneider (2001) suggest that spatially specific information is needed on the vulnerability of specific population groups to allow them to think more specifically about climate change. Yet as Hoffman (2012: 37) explains, even though a scientific consensus may exist - for example on the health risks associated with smoking - it is "through a process of political, economic, social, and legal debate over values and beliefs, a social consensus" will arise. Knowledge of an issue alone does not lead to behaviour change (cf. Hulme 2009). Instead climate change understanding is shaped by lay knowledge, "by the associations of the climate in everyday lives ..." and are "circulated - modified by a perhaps tangential, infrequent, incomplete, partial encounter with 'science"' (Geoghegan \& Brace 2011: 294). Geoghegan and Brace (2011: 295-96) call for a more open understanding of climate change, to set "aside the relatively deterministic understandings of climate and the ways it might change offered by the natural sciences" allowing an understanding of "how it might be grounded and localized through the concept of familiar - embodied, practised and lived".
As individuals "do not have a set of socially accepted beliefs on climate change" (Hoffman 2012: 32 ), any attempt to understand and interpret climate change knowledge requires a thorough "political, economic, social, and legal debate over values and beliefs" through which social consensus emerges (Hoffman 2012: 37). Social consensus is contingent upon shared mutually constituted understandings around an event or series of issues. Hoffman (ibid.) suggests that individuals are rationally bounded through their own personal experiential ideology, which is formed by their personal belief systems. Debates surrounding climate change are therefore not based solely on the reception, interpretation, and understanding of scientific evidence, but also on the production of personal values, ideologies, and culture. Values are often considered a "guiding principle in the life of a person" or presenting an "abstract set of moral principles" to only show some of the "multiple conceptions of human values that exist across these multiple literatures" (Corner et al. 2014: 412-413). Corner et al. (2014: 418) conclude that clusters of values around self-transcendent and altruistic ideas "are strongly predictive of positive engagement with climate change". Hoffman and Jennings (2012) state that such 'ideological filters' are being ignored in climate change debates, and Hoffman (2010) further suggests that climate change-related policies should target the way business leaders think and how their values could be changed. He thinks that there needs to be a shift in the values that guide our decision-making more widely in society and not just in businesses. Critiques of personal value systems are evident in the work of both Rorty (1989) and Glass (1993). Hekman's (1999: 19) interpretation of Rorty's Contingency, Irony and Solidarity suggests that "embracing a non-essentialist position need not cause any problems for the coherency of individual actions". More specifically, Rorty (1989) argues that beliefs - referents of an individual's ideological position - are the organising foundations of regulatory regimes that determine actions, "even if those who hold them are aware that they are caused by nothing deeper than contingent circumstances" (Hekman 1999: 19). Individuals therefore formulate belief systems they believe to be stable, solid, and truthful to themselves, which can be affirmed by everyday actions and not necessarily founded on contingent scientific interpretations of future climate scenarios. Individuals act on the basis that they know a deep self, which in turn is 
predicated on firm and believable interpretations of the world around them. It is for some of these reasons, where underlying "culturally embedded assumptions, imaginations, and practices" occur, that climate change communication can never be "effective communication per se" but only offer an opportunity for someone's "own logic of participation" (Nerlich et al. 2010: 106-107).

Patenaude (2011) and Goodall (2008) suggest that the business community is not treated as an audience of interest, while climate change equally is neglected by business schools. Patenaude (2011) found that climate change issues are not addressed in business schools, which create future business leaders who are climate illiterate. Goodall (2008) discovered that leading business journals fail to address climate change in their articles: only three out of the top-30 management journals listed in ISI Web of Knowledge addressed climate change or global warming in article titles during the 19922008 period inclusively. Businesses replace climate change with environmental issues that are directly experienced and, consequently, perceived as more important (Reinhardt \& O'Neill Packard 2001: 3; Goodall 2008; Patenaude 2011; Wolf \& Moser 2011):

\footnotetext{
"While many companies may still think of global warming as a corporate social responsibility issue, business leaders need to approach it in the same hard-headed manner as any other strategic threat or opportunity."
}

Instead, engagement with climate change is considered by many businesses as a matter of CSR. The idea of CSR is to enable businesses to meet the expectations and needs of a society whilst making a profit (Carroll 1991; Loew et al. 2004). However, Porter and Reinhardt (2001: 1-2) point out that climate change is too "tangible and certain" to be addressed by such a philanthropic approach. They suggest a strategic approach, allowing mitigating climate change-related costs and reducing vulnerability to the effects of climate change, is needed.

\section{Method}

This study examines critically over a 3-year time period 30 SMEs across sectors in Cornwall, UK, which engage with climate change knowledge and 5 Innovation-Support-Organizations (ISOs) ${ }^{2}$ which communicate climate change knowledge. Cornwall, a county in the South West of the UK
(Fig. 1) with a population of about 537,400 (SQW 2012), was together with the Isles of Scilly classified as an 'Objective One' region by the European Union (EU) in 2000 (Cornwall Council 2013). Cornwall therefore received significant support through EU Convergence funding until 2013, which led to the current 2014 EU Growth Programme. 25,495 of the 25,540 Value-Added Tax (VAT) and/or Pay As You Earn (PAYE) based enterprises in Cornwall were classified as SMEs in 2012, of which $84 \%$ had four or less employees ${ }^{3}$ (Office of National Statistics 2012). The majority of Cornish businesses are active in agriculture, forestry and fishing, retail, construction as well as accommodation and food services, sectors, which are closely linked to the natural environment. This can be explained by the county's natural resources and attractions: Cornwall has a coastline of $697 \mathrm{~km}$ and the majority of its landscape is classified as an "Area of Outstanding Natural Beauty" (AONB) (Cornwall Council 2011). Cornwall is expected to experience an increased frequency of changes in temperature and precipitation (Murphy et al. 2009). Under a medium emissions scenario, the central estimate of increase in winter mean temperature in the South West by 2050 is $2.1^{\circ} \mathrm{C}$; it is very unlikely to be less than $1.1{ }^{\circ} \mathrm{C}$ and is very unlikely to be more than $3.2{ }^{\circ} \mathrm{C}$ (ibid.). Under the same scenario, the central estimate of increase in summer mean temperature in the South West by 2050 is $2.7^{\circ} \mathrm{C}$; it is very unlikely to be less than $1.3^{\circ} \mathrm{C}$ and is very unlikely to be more than $4.6^{\circ} \mathrm{C}$. Relative sea-level at Newlyn (Cornwall) is expected to increase with respect to 1990 by $24.5 \mathrm{~cm}$ by 2050 according to the medium emissions scenario (UKCP 2009).

To identify SMEs in Cornwall that engage with climate change, an actor-network approach was taken. The researchers therefore took part in a variety of formal and informal business networks and climate change related business events. We also conducted open interviews with key informants on the general business infrastructure and climate change activities of businesses and ISOs in Cornwall. This actor-network approach served as a tool to gather an overview of the local climate change and business community identifying key issues and knowledge, therefore establishing "a preliminary research net" (Crang \& Cook 2007: 17). Knowing to whom we would gain access was therefore unpredictable and scheduling the data collection in advance was very difficult. This "controlled opportunism" allowed evolving research where research is non-linear and data collection and 


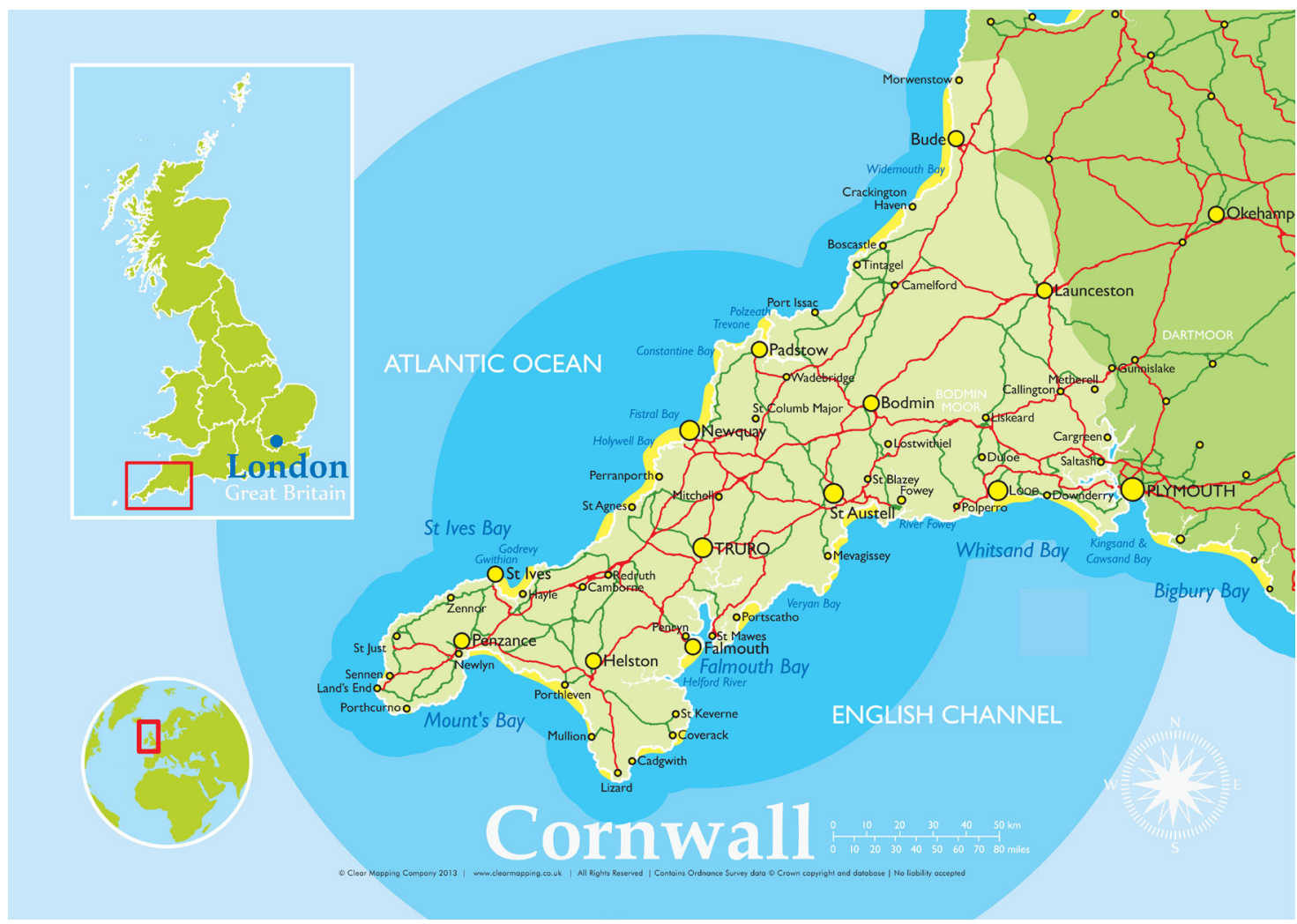

Fig. 1. Location of Cornwall.

theory are not separate (Eisenhardt 1989: 539). A few selected SMEs were also contacted directly due to their known reputation to be engaging with climate change. The participating SMEs are therefore from across sectors and vary in size, from one-person micro businesses to businesses with up to 250 employees.

30 business leaders and 29 representatives from government and ISOs participated in the study. This allowed us to: (1) explore climate change knowledge from the communication and business side alike; and (2) uncover the complex construct around climate change formed by individual experiences and social processes (see also Eisenhardt 1989; Winchester \& Rofe 2010; Hulme 2011; Hoffman 2012). This approach revealed norms, power structures, and expectations in this societal context (Dowling 2010), and emphasized the relational reality of business decision-making in SMEs through looking at the "own logic of participation" of businesses (Nerlich et al. 2010: 107).

To answer the research questions we draw on empirical evidence derived through qualitative research methods of: (1) in-depth semi-structured and open interviews; (2) participant observations; and (3) practitioners' workshops. This paper mainly draws on the qualitative research data derived from the semi-structured interviews and open interviews. We explore why and how SMEs approach the gap that exists between climate change science and business engagement grounded in the diverse literature of climate change science communication and business studies. The semi-structured and open interviews focused on: (1) the understanding of business leaders of climate change knowledge; (2) sense-making of this knowledge to allow decision-making; and (3) the reasons for the engagement with climate change. We used open 
questions to allow participants to speak about issues not necessarily addressed by the interview questions and to emphasize issues that they perceived as important. The semi-structured interviews therefore allowed us to understand the reality of climate change and business as perceived by the participants.

Transcripts and field notes were initially sorted into different themes according not only to the research questions but also according to themes the participants and observations had identified. The themes were then analysed in respect to the business characteristics and the business environment. After the data were coded within their respective themes, we used content analysis to look into the research questions in more detail. After having received a first impression of the data through mapping the answers into different themes and subthemes in Excel, we established a detailed content analysis.

\section{Climate change as a future issue}

Our qualitative research undertaken identified that the physical impacts of climate change are a future concern for SMEs. The majority of 'engaged SMEs' have not yet materially/physically been impacted by climate change; however, the business leaders construct a current link between possible future impacts of climate change, economic activities and well-being.

Only two from 30 interviewed SMEs state that their businesses have experienced physical climate change impacts. One of the business leaders of these two businesses explains that her hotel is located at the edge of a beach on the north coast of Cornwall, and experienced severe flooding to one of their main buildings during a storm event. She explains:

"... because of where we are on this beach we are completely at the mercy of the weather. It impacts us so much that we can't escape climate change. .... Our ... restaurant on the beach got washed away a few years ago in a massive storm. We had just finished refurbishing it and then had a really big storm with a really high tide and it took it out completely. It was devastating. We lost that and a big chunk of our business and then had to rebuild it. Obviously the insurance for that is now very different to what it was. If that would happen again we couldn't afford to rebuild it." (AY.H., Business Leader, interviewed in 2012)
This business leader makes sense out of climate change through interpreting what she believes climate change could be whether or not it might just be natural climate variability. Extreme storm events are attributed to climate change and enable the business leader to develop an understanding of what this climate change would mean for their future business activities. What this business leader describes here as engaging with climate change is often understood as being able to cope with e.g. environmental external stresses and thus becoming resilient to future stresses (Gallopín 2006). The quote also displays that the SME experienced financial costs such as the expense of rebuilding flooded property or having to pay higher insurance premiums, but also experience the 'un-situated' climate change risks (Hulme et al. 2009: 201) in a very specific, local, and individual shape. Physical climate change impacts give SMEs a specific way of knowing this "messy, non-linear and diffuse" (Boykoff et al. 2009: 1) issue and at the same time triggering specific future fears. A storm event gives business leaders an idea of how this "critical yet unexamined" (Geoghegan \& Brace 2011: 291) future might look as not only policies, intermediaries or scientists "beat a path through events still to come" (Fish 2009: 2-3). Although the other 28 interviewed SMEs indicate that they had not materially experienced climate change, they explain that they can see climate change as being relevant to them in the future through impacting socio-economic systems:

"Climate change may affect us where the wheat
crops are growing because we need it for our pro-
cess. If we can't get it, that will affect us. Our head
brewer definitely looks at these things. Prices get
affected. They have to buy years ahead." (RN.F.,
Business Leader, interviewed in 2012)

Most participants go on to explain the links they can see between their business and the natural environment. This business leader for example understands climate change through his business practices and how these are placed in the environment:

"Our business is very aware of climate change and the impact it can have on our local environment and on the things that so many of our customers come to visit us; the beaches, the green grass for walking, enjoying the area around. There was an article on BBC today that people love being by the seaside and that it improves wellbeing. That's one of the reasons people come to us; be- 
cause we can give this experience. If we don't take care of our environments then people won't come back for it. It keeps us a business and we are very linked with our environments, our surroundings and the impacts of climate change whether it's drought or rise in sea level." (CE.B., Business Leader, interviewed in 2012)

It is clear that even businesses that have not materially experienced climate change can still make the link between possible impacts of climate change and business continuity. Whether or not a storm event or change in crop growth is actually connected to climate change is irrelevant for these decision makers. Business leaders create their own understanding of what climate change is and could be, where the exact definition of this largely physical phenomenon does not play much of a role. The actual sense-making processes create a form of life for climate change. This is a description that stems from Wittgenstein (1958), who explains that words find their meanings through use within a societal setting and are not in need of a precise definition. These businesses reassess their business operations regardless of specific known impacts and instead treat climate change similar to an innovation that is important to take without knowing specific outcomes, an ability many businesses lack, as Hoffman (2004) suggests. These findings also show that for these SMEs mitigation and adaptation strategies on climate change shape and are shaped by lay knowledge, which go "beyond science as a community of practice and scientists as the producers and arbiters of a particular kind of knowledge" (Geoghegan \& Brace 2011: 293), and that the actual encounters with climate change are very context-dependent, complex, and diverse. It also confirms Geoghegan and Brace 's (2011: 297) assumption that climate change is "a relational phenomenon that needs to be understood on a local level, attending to its distinctive spatialities and temporalities" (Geoghegan \& Brace 2011: 297). Our findings suggest that knowing climate change goes beyond knowing scientific facts and is instead "constructed through memory, observation and conversation" (Leyson \& Geoghegan 2012: 64). Most businesses view climate change more as an opportunity to prepare for the unknown than a risk, while placing climate change in the wider complexity of socio-economic system(s). The data also suggest that especially businesses that do not fear the direct material force of climate change have more opportunistic and positive associations with climate change. Businesses in our study view climate change as a futurity that might impact the business indirectly through growing energy prices, changing supply, and demand conditions. The participants refer to how they have adapted their business models to the possible future implications of climate change. This business leader explains how he envisions the future:

"When we made this place, we designed it to be used in a number of ways. We might have refugees and not tourists in the future." (CS.J., Business Leader, interviewed in 2012)

He also explained how he deals with these "distant futures" (Geoghegan \& Brace 2011: 292):

\begin{abstract}
"There is a massive gap between understanding the world for what it is and what you would like it to be. We don't have a crystal ball. The things that we would really like to know, nobody can ever tell us. When will we have a good summer, or from where can we import things in the future? So it's more about enforcing the things that we know about - reduced availability of resources and working around that. That should make you more resilient to impacts of climate change." (CS.J., Business Leader 2012)
\end{abstract}

We can see here that businesses confront climate change and make it their 'own' to fit decision-making processes, business strategies, and worldviews. Climate change engagement it about how making the change in the climate relevant to someone's everyday decisions. Lewontin (1992: 86) describes such approaches as having a "constructionist view of life"; business leaders and their organizations "construct their environment out of bits and pieces" (ibid.) as organisms do in order to be able to cope with the complex, ever-changing, and uncertain nature of climate change. Business leaders act similarly to this to be able to adapt to the changing environment through imagining futures while accepting that the science is incomplete. Another business leader explicitly expresses that even though they have not been materially impacted by climate change he still engages with it.

"Climate change hasn't impacted us.... Scientists can measure it but as normal human beings we would have to experience climate change. It requires a certain leap of faith and insight to actually be able to say that this is how the world is going to be in 50 years time. But it's difficult for us. The simple thing for us to understand is that if you keep using stuff, it will run out." (SN.T., Business Leader \& Government Worker, interviewed in 2012) 
He continues to express what some other business leaders have expressed in the interviews: business leaders whose businesses are not directly dependent on the natural environment believe that often the market with its customers does not yet demand a business to mitigate, and/or adapt to, climate change, but should do and soon will do.

\begin{abstract}
"Customers do not demand the green agenda in tourism. It doesn't really make a difference to customers.... We think we should and put resources into it. There is no demand now, but we think it is an investment in the future. After customers have been to one of our houses they might be more aware next time. .... Then there is a commercial driver in the future." (SN.T., Business Leader \& Government Worker, interviewed in 2012)
\end{abstract}

This shows that even though climate change has not "manifested itself physically yet" (Leyson \& Geoghegan 2012: 57) for most business leaders climate change can encompass high current relevance. The above data show business leaders connect diverse issues with climate change not commonly understood as climate change related: crop growth, insurance premiums, electricity costs, environmental assets. They link these to (risk) planning, profitability, and economic costs but perceive climate change as a future issue, less of a current concern, more as an opportunity than a threat. These results contradict Norgaard's (2006) findings, which suggest that people avoid thinking about climate change as it makes them feel helpless, guilty, and threatened. Wilson (1997) links information behaviour to social cognitive theory, where selfefficacy determines behaviour, derived from the field of psychology. He refers to Bandura (1977: 193) who states that "the strength of people's convictions in their own effectiveness is likely to affect whether they will even try to cope with given situations". He therefore hypothesizes "that one of the motives for information-seeking is to gain information to improve one's self-efficacy in coping with problems of whatever kind". The businesses examined in the study might feel that they have enough self-efficacy to engage with climate change. Placing this in relation to their personal values on climate change means then that their situation and identity do not negatively relate to their "standard of living. .... To recognize greenhouse gases as a problem requires us to change a great deal about how we view the world and ourselves within it" (Hoffman 2012: 33). It also shows that they create lay knowledge on climate change through their imagination of how reality ought to be. The findings emphasise that having the capability to mitigate and/or adapt to climate change, in this case through the engagement of the businesses, creates a positive and opportunistic outlook on climate change. This confirms Rogan et al.'s (2005) findings that people feel satisfied, encouraged, and experience positive self-esteem about themselves and climate change when having been involved in environmental conservation or restoration experiences. Climate change is primarily a future issue, the importance of which can already be understood and lead to engagement in the present.

\section{Engagement due to personal values}

$97 \%$ of the participating business leaders indicate that their initial trigger to make climate change relevant to the business is related to their personal values. The following business leader explains why he started engaging with climate change:

\begin{abstract}
"I guess it was personal interest and personal conviction which kind of span out to have business benefits as well. .... Initially it was my personal interest but the more you get into it the more you see the business benefit." (MK.P., Business Leader, interviewed in 2012)
\end{abstract}

His personal interest in climate change triggered his initial engagement and then created a business benefit. Most other business leaders show very similar links between their initial engagement and their personal values. These findings show that personal values determine decision-making in SMEs and that engaged business leaders fulfil their role as leaders, which Dunphy et al. (2007: 322) describe as being a "...source of influence in a complex changing reality. Nevertheless let us not underestimate the potential; transformative power that we represent". This supports recent research that too often business literature and current climate change communication assume self-interested, profit-maximizing individuals lead businesses (cf. Hoffmann \& Jennings 2012; Corner 2014). Instead, decision making on climate change is strongly linked to individuals. The following business leader explains the closeness between personal values and decision-making in SMEs: 
"There are more and more personal convictions (driving business decisions). Smaller businesses have that flexibility. A director of a small business can take that business with him, whereas a bigger business finds that difficult." (TY.S., Representative from an ISO, interviewed in 2012)

These findings provide evidence that some people invest in supporting pre-existing beliefs (Hoffman 2012) when engaging with climate change. However, personal convictions of participating businesses leaders are only the initial trigger and financial aspects do play a role. One of the business leaders explains this. He believes that engaging with climate change requires a business leader to be opportunistic and can only be driven by personal values:

"I think it's one of those issues that, to make it part of your core business, you have to be very passionate about it. Unless people find that passion they won't see the relevance. It is really down to personal passion for such an issue. Making that bolt move to have it part of your business...can be quite difficult. People don't see the relevance and care for it. .... I think it's personal interest and financial sense. ... We would not have built our hotel in the way it is if sustainability had not been a key passion for the directors and a vision to future proof ourselves." (AY.H., Business Leader, interviewed in 2012)

Another business leader explains that often engagement with climate change does not immediately create benefits for the business, but that through his engagement driven by his personal interest business benefits were created:

"In terms of how that works with our business is that, in some respects, it doesn't. It's something that I was just really interested in - looking at how we can become more sustainable as a company. But from that, it actually created business opportunities for us. .... It was something that we wanted to do because we felt like we should be doing it. It's given us business benefits at the same time. So to begin with it was my own conviction, .... I guess it was personal interest and personal conviction which kind of span out to have business benefits as well." (MK.P., Business Leader, interviewed in 2012)

Personal convictions allow business leaders to be opportunistic/innovate beyond what they would normally practise. Only later does this behaviour yield financial benefits. Kotter (2001) however suggests leaders often fail to cope with change because they feel powerless. Norgaard
(2006) similarly suggests that people avoid thinking about climate change as it makes them feel helpless, guilty, and threaten their individual and collective sense of identity. The helplessness expressed in our study is less related to the personal level, but more to problems of understanding climate change science, accessing, and translating information. There is here no evidence for a value-action-gap between engagement of SMEs and the values of business leaders. One of the few studies on the motivations of SME leaders to engage with climate change has also shown that the decision to engage with climate change through business practices is due to personal values (Williams \& Schaefer 2013). Business leaders often derive their personal interest in climate change related issues through personal experiences. This business leader explains:

"When I grew up, there were hardly any trees around here. It really would not grow. It was so windy, and so much salt in the air. The climate has certainly changed. The predominant winds are no longer so much from the South West. They are much more variable and it is amazing for me to see what is growing around here where there wasn't very much at all. I think that is quite noticeable. We all know that we are getting much more weather extremes as well. Some of the rainstorms. You get so much rain." (IN.D., Business Leader, interviewed in 2012)

In the family-run SMEs of our study the business leaders are able to 'experience' climate change, which "is difficult to grasp" due to "... an accumulation of data over a timeframe that is perhaps a generation in length" (Geoghegan \& Brace 2011: 291). This is due to the fact that through running a business over several generations business leaders are able to 'experience' climate variability as it has perhaps impacted the business in the past. Experiences and knowledge passed down through generations, enable businesses to overcome the immediate timescales of human behaviour to grasp climate change as an issue of individual importance (cf. Hulme et al. 2009; Geoghegan \& Brace 2011). The business leader continues:

"I guess I've been interested in energy, insulation, and climate change since I was a student. My dad started this business, now I run it and even my son works here." (IN.D., Business Leader, interviewed in 2012) 
This business leader describes here what Leyshon and Geoghegan (2012: 58) term a "familiarity with place" that results from "a daily encounter with" climate change. To construct climate change through remembering and imagining the past in relation to a particular place is similar to Rogan et al.'s (2005) findings that people use places as reference points to the past to understand the environment. Business leaders from family-run SMEs feel very attached to the business and their local community. It is part of their identity to take care of the environment and society around them. These SMEs have the ability/advantage to conceptualize climate change as a potential threat to their business activities, self and space overcoming the disproportion of "scale between climate change and individual actions" (Patenaude 2011: 267) and the much discussed feeling of helplessness. For these 'engaged SMEs' imagining the future poses less of a problem as they are able to overcome the "inability to conceptualize time beyond the periodic frame of our own lifetimes, or even a generation, and to imagine distant futures in which the climate might be altered" (Geoghegan \& Brace 2011: 292) via imagining an infinite lifetime for the business. These suggestions are confirmed by similar statements from other business leaders:

\begin{abstract}
"I fell into it because I was a corporate finance lawyer and one client was one of these climate change businesses. Suddenly it clicked. I was always fairly aware. ..... But then I had small children and suddenly I was doing something for which I could use my discipline and expertise and actually believe in it. It made more sense. .... I have a more generic interest in sustainability that comes from me living down here for 30 years, amongst a community where I bring up the next generation of two daughters who might want to do the same job." (KE.A., Business Leader, interviewed in 2012)
\end{abstract}

Some other business leaders draw a link between business engagement, education and intergenerationality. This business leader for example describes how his peer-businesses are driven by the personal values and education of individuals:

"... it's the responsibility of the owner of the business. It comes down to if the owner believes climate change is an important part. I think in Cornwall there are many of those because they see it. Somebody like Tom for example has a strong belief in being involved in lots of different things. He enters it at the strategic level and then tells his staff. So rather than taking his staff of the core business he'll do it and then rely on his core business to be run by staff. If Tom is concerned about climate change, then how does he influence change? .... Personal choice and personal decision play a major part! If you change the structure of a business then education is probably as important. How important is climate change? That's based on education." (AW.W., Business Leader, interviewed in 2012)

The business leader explains that engagement with climate change is linked to individual businesses leaders and their values. Additionally, their personal interest is linked to previous education on climate change. For another business leader it is however the changes in the environment that he perceives and experiencing with those changes that allow engagement:

"I see the changes and I respond to them on a small level but also through my own experience. Trying plants in certain areas. In a way I'm doing my own primary research. I'm an environmental business." (ME.W., Business Leader, interviewed in 2012)

Our findings therefore support Hulme et al.'s (2009: 197) belief that climate change finds its form through experiences, social learning, and cultural interpretation, and emphasises that its actual meaning is "informed by emotion, memory and a sense of place that comes in part from familial ties" (Leyson \& Geoghegan 2012). Such business leaders have lay knowledge on climate change accumulated over generations and enabling development of a personal and individual understanding of climate change, not just in terms of time but also local space. This allows business leaders to imagine this social, unexperiencable construct of climate change over "past, present and future" (Leyson \& Geoghegan 2012: 59). The data show that personal values and experiences are important to understand climate change while also constructing determinants on whether or not to let climate change play a role in decision-making processes. Interestingly, several studies have previously shown that people struggle to follow up personal values on climate change (cf. Kollmuss \& Agyeman 2002; Whitmarsh et al. 2011). Tilley (1999) demonstrates that owner-managers of small firms struggle to follow up environmental attitudes with environmental practices. She suggests that it is difficult for businesses to associate business practice with environmental damage, but that more importantly a conflicting message on envi- 
ronmental solutions causes this gap. For our research however participant's values lead to action. Our continuous interaction with the business leaders over a three-year period showed that the majority of business leaders demonstrate true commitment to, and action on, these values. The business leaders regularly take part in climate change related business meetings, attend climate change related events by ISOs, and actively develop mitigation and adaptation actions within their businesses. Of the 30 participating businesses, 86\% mitigate climate change through, for example, using renewable energies, waste management, and/ or giving employees incentives to reduce their work related carbon footprint. $97 \%$ of the businesses adapt to climate change by adjusting, and/ or developing new products and services, and $90 \%$ of the businesses also communicate the need for mitigation and adaptation strategies to the local communities, other businesses and their employees.

This importance of personal values for climate change engagement is emphasized by the Intergovernmental Panel on Climate Change's (IPCC) latest integration of philosophers within its panel. The philosopher Broome (BBC 2013; see Broome 2012) stated recently in a BBC Radio 4 interview that integrating values in the climate change debate challenges the basis on which to argue as it raises moral questions. For some SMEs the choice between profit and climate change starts with a moral one. Why do some SMEs decide to ignore climate change? One could suggest that they simply have the wrong values, because values, according to Broome, see that there might be a disadvantage to someone or something else through e.g. emitting carbon (cf. BBC 2013). Personal values and experiences in respect to the communication and engagement of climate change have rarely been considered in studies of business engagement with climate change. Hoffmann and Jennings (2012) point out that the main route to engage businesses with climate change is through pricing carbon, based on the principle of 'homo economicus' ignoring issues on decision-making or values. Our findings presented here criticize this type of climate change communication, which traditionally presents climate change on premises that: first, SMEs understand climate change in absolute terms instead of through individual and very personal narratives; second, SMEs are institutions mainly driven by pure profit maximization; and third, lessons learned from other disciplines on be- haviour change or climate change communication are irrelevant. The findings further confirm existing criticism that ideas on business engagement with climate change are too scientific (Hoffman 2004; Goodall 2008). We suggest that climate change must be brought to businesses through creative ideas and addressing values and beliefs. The background of the business leader can therefore explain this personal conviction as many of the interviewed business leaders show the following characteristics: (1) a strong feeling of identity to a specific location/region; (2) being educated about and aware of the relevance of climate change; (3) the ability to experience and conceptualize climate change beyond our own lifetime through the lifespan of the business.

\section{Business engagement with climate change within current socio-economic systems}

While the above findings show that personal values of businesses leaders can trigger engagement with climate change on behalf of businesses, business leaders struggle to manifest those values within the current socio-economic system(s). More than half of the interviewed business leaders discuss greater societal concerns when being questioned on climate change engagement. This business leader explains that his company aims to create a better world:

"My business has a very strong social objective and that is to make the world a better place. ... And the environment is a very important part of that.... it's not just about dealing with the issue as a global warming issue, it's about looking at things like the motivations in people's lives." (RT.W., Business Leader, interviewed in 2012)

Climate change is seen as connected to other societal and economic choices people make. The business leader explains that he views climate change as an issue interconnected to how he sees himself and his interests:

"I've been interested in climate change for years; actually about 10 years. I'm very interested in W. F. Schumacher. So that got me thinking many years ago about choosing more for less and that we are living on an unsustainable path. I'm very interested in environmental issues. I tend to see it as a social issue." (RT.W., Business Leader, interviewed in 2012) 
Most of the other business leaders also stress their awareness of the link between business success, society, and the environment. Another business leader explains that he aims to create social change through his climate change engagement. He tries to stimulate adaptation and mitigation activities in the wider business community and society (cf. Hoffman 2012).

\begin{abstract}
"The main idea with our company is our passive activism. The way we engage with climate change allows our clients to open their eyes a bit more to the idea that they could make a difference. .... We talk about climate change but actually it's about social change as well. Understanding what you are part of." (MT.H., Business Leader, interviewed in 2012)
\end{abstract}

These two business leaders emphasised an understanding of the embeddedness of businesses within both society and the natural environment. This fits with the growing belief that businesses are responsible for, and dependent on, a healthy society. Participating SMEs show that they want to create physical, social, as well as mental well-being (Sangmeister 2009), while aiming to create profits that simultaneously raise the quality of life (Brundtland 1987; Hart 2007). The quotes also express the desire of the business leaders to be responsible citizens. Engagement with climate change allows them to do so and endorse their personal identity. Most of the participating business leaders express a need for change in the UK's culture on consumption and tackling climate change. This participant expresses:

"I think we are uneducated. We don't seem to approach things. I had quite a lot to do with Germany - friends, skiing, etc.. I did pick up a feel for the way younger people were thinking about climate change. It's sad that our society is not at all interested in this." (IN.D., Business Leader, interviewed in 2012)

The data indicate that business leaders believe climate change is not accepted/integrated in the current political and economic system(s) due to the UK's culture and society. This business leader sees an important responsibility for changing political and economic system(s) coming from society through changing values:

"I think, it's culture. .... We want more and buy more and actually the way our society functions is fuelled by credit.... We've got this culture to work really hard for reward and then we spend all of it; play hard. That is not sustainable. It's not the key to happiness. The key to happiness is probably to be more resourceful. .... But we don't get that in our country. .... What needs to happen is for communities and businesses driving it forward. ... We are talking about businesses and communities. Everyone. .... Climate change is exactly the same." (RT.W., Business Leader, interviewed in 2012)

While he explains that society has an important framing role for political and economic framework(s), some business leaders go on to request a shift in the country's culture. This business leader explains the urgent need for a culture change which should be driven by businesses and governments alike:

"I think there are a lot of small businesses who want to be more responsible and when those companies grow that will bring a culture change. We have to change how we are doing business. It will be ripples from bottom to top, top to bottom, until it's all mainstream." (CE.R., Business Leader, interviewed in 2012)

The above show that engagement with climate change is difficult for SMEs due to the current way businesses are thought to behave and the political and economic system(s) in which they are embedded, despite their desire to protect the economy and society. For these business leaders climate change has entered their belief system, something Hoffman (2012) raises in his article 'Climate science as culture war', where he (ibid.: 33) points out that climate change really is a debate over "values, worldviews, and ideology" and suggests (ibid.: 32) that people adopt a view on issues, that "reflect their identity, worldview, and belief systems" to reinforce the connection with their referent groups and to strengthen their definition of self. The evidence from our interviews presented here suggests that the wider belief system of individual business leaders reinforces the engagement with climate change. In the case of Cornwall where economic actors emphasise the importance of personal relationships and where, according to this business leader, "a sense of place ..." exists and, "... businesses go into things naturally", the informal and formal networks of personal relationships encourage such a climate change belief system. These 'engaged SMEs' have managed to establish "a set of socially accepted beliefs on climate change; beliefs that emerge, not from individual preferences, but from societal norms" (Hoffman 2012: 32) around them. Climate change en- 
gagement and the associated communication should be connected with a sense of place and the wider (business) community. Rogan et al. (2005) support this claim through their study on the relationship between sense of place and a changing natural environment. They found that there is a growing sense of responsibility towards the local environment especially when people can link the place to family experiences. This sense of belonging brings a sense of responsibility leading to engagement with the environment, which then fulfils people's own goals (Rogan et al. 2005). Our findings deliver new insights that climate change is an ethical debate over values and culture, something that must be learned, not only for the communication of climate change, but also the modelling of climate scenarios and scientific debates about geoengineering. This shows signs of a long needed change to realize more long-term and meaningful mitigation and adaptation to climate change, something Jackson (2009) describes as "prosperity without growth", criticizing the current model of economic success based on "relentless consumption growth" (Jackson 2009: 489) making combating climate change impossible, while calling for a more "sophisticated form of capitalism" (Porter \& Kramer 2011: 12). Business leaders that engage with climate change have a high responsibility for the environment and society due to being in a leadership position wanting to "do business while doing good".

\section{Conclusion and recommendations}

This paper has addressed the lacuna of work on how business leaders of SMEs conceptualize climate change and how their understanding of climate science influences their decision-making and business practice. This research approached the topic from the perspectives of SMEs and in particular focused on how they understand and make sense of climate change. Methodologically this enabled us to gather context-dependent insights into why some businesses manage to engage with climate change. Through this we examined critically Geoghegan and Brace's (2011: 297) request for a more relational approach towards climate change "that needs to be understood on a local level, attending to its distinctive spatialities and temporalities". The study illustrates that business leaders' mitigation and adaptation strategies are shaped through their personal lay knowledge on climate change and do not appear to be formulated through interpreting specific scientific knowledge and/or business reasoning. This occurs for two main reasons, first, climate change decision-making is often predicated upon an individual's identity and value systems (these are often elided in the business studies literature), and second, decision-making is focused on wealth creation for the business.

In this paper we have demonstrated that climate change is a(n) (un)known futurity for SMEs. Business leaders conceptualize climate change through both imaginative and experiential lenses positioning their businesses in relation to past and future existence(s) (Geoghegan \& Brace 2011). Those business leaders who believed they had the capability to make a difference to climate change had a more positive and opportunistic outlook towards adapting to potential change. In this way, climate change is a very individual, sense-making process for businesses. Business leaders understand and situate climate change within personal values and belief systems to produce their own personal lay knowledge of climate change, which in turn influence their decision-making. Glass (1993) provides perhaps the single most important critique of the way value systems are constructed. He argues that they are not fragmented, ruptured, fluid or forever in the process of becoming, as this is predicated on disorientation, disembeddedness, rootlessness, and sense of being incomplete. Instead, Glass makes a strong case for the unity of self-knowledge as a necessary requirement for leading any version of a good and satisfying life. A stable value system for Glass (1993: 48) is necessary because it enables individuals to locate themselves in the world: "it defines emotional and interpersonal knowledge; it frames the self in a historical and situational context". Glass's research usefully draws attention to the idea that individuals must necessarily experience themselves as a coherent entity, historically located, and contingent, but enduring through time. This coherent self allows them to place themselves in context, to cope with the contingencies of existence, such as climate change. Importantly, we argue that the production of climate change knowledge is in itself not radically contingent, but rather a referential frame within a contingent world. This understanding of how climate change science is understood by business leaders is fundamentally at odds with deficit models of knowledge exchange, i.e. without changing individuals' value systems we should not expect climate knowledge to be absorbed and enacted upon. Hence causal reasons for 
business engagement with climate change are lay knowledge dependent and these knowledges are derived from personal values, space, and place identity.

We introduced the concept of an 'engaged SME' to represent those organisations which voluntarily foster and encourage further engagement with climate change issues. Our findings suggest that business engagement with climate change is primarily a function of company directors pursuing their own personal value systems rather than a response to climate change science per se. SMEs do not need to consistently hear about the latest climate change science. To enhance the number of SMEs engaging with climate change, to maximize the potential value of climate change for the economy and establish a low carbon economy, climate change communication instead needs to target the personal values of individuals. Business leaders in our study suggest that this can be achieved in four interrelated ways: first, by focusing attention on climate change impacts at a regional level, second, drawing attention to potential "feel good factors", meaning the benefits to (the local) society and economy, third, raising awareness of the potential financial benefits that might accrue to the business if they mitigate or adapt to climate change, and finally, improving the facilitation of knowledge sharing activities amongst SMEs.

It could be argued that the relatively small research sample of 30 business leaders limits the wider relevance of these research findings, but due to the lack of literature on business decision-making and climate the study does deliver interesting and important insights into this unexplored field. The use of a qualitative research approach may involve researcher subjectivity; this was addressed through a continuous interaction with the business leaders by monitoring business meetings, conducting interviews with communicators that work with the participating businesses, and by triangulating various different research tools. This has allowed a much deeper engagement with individuals actively involved in the business community. The lack of prior studies in this research field means that direct comparison to previous findings is absent and hence there is a possibility that the specific conditions that apply to Cornwall preclude wider applicability of the findings. However, there appear to be no obvious reasons why similar businesses elsewhere in the UK or indeed Europe should have radically different characteristics. By concentrating on engaged businesses it has been possible to establish just what it is that drives these businesses to take an active interest in climate change, and by doing so we have shown that attempts to involve a wider range of businesses is very unlikely to be successful by concentrating on trying to communicate the science per se, or improving the 'quality' of the science that is available.

The research reported here demonstrates that business understanding of climate change emerges around transient understandings and knowledge exchanges. Climate change scientists as well as climate change intermediaries do not need to communicate climate change science to SMEs but instead need to comprehend the value-driven audience of SMEs. In our study, SME business leaders interviewed here pursue strategies to safeguard economic, ethical, and philanthropic expectations of themselves and their organisations, something largely unrecognized and consequently ignored despite reflecting the true cultural characteristics of this business audience. Climate change communication therefore needs to go beyond thinking about potential financial benefits for SMEs and pursue Hoffman's (2012: 32) sense that "we must acknowledge that the debate over climate change, like almost all environmental issues, is a debate over culture, worldviews, and ideology". To create formal and informal knowledge making by SMEs requires a shift in emphasis in scientific communication strategies by marrying "governmental topdown frameworks and goals" "with local geographies and 'bottom-up' local desires and aspirations" (Moir \& Leyshon 2013: 1020).

Climate change communication needs to be more aware of individual audiences (cf. O'Neill \& Hulme 2009) and acknowledge that climate change science is as much a discussion about values, cultures, and beliefs as it is about modelling climate variability. To inculcate climate change communication into popular culture and belief systems requires, Hoffman (2012: 6) argues, "a violent debate among cultural communities on one side who perceive their values to be threatened by change, and cultural communities on the other side who perceive their values to be threatened by the status quo". Too often climate change is still seen purely as a scientific debate, where climate science is being misappropriated as an economic and political instrument (Cook et al. 2013). Instead a progressive space for discussion and dialogue on climate change needs to be opened up in which socially informed and value- 
laden knowledge can be exchanged, because ultimately political regulation does not depend on governments alone but rather on consensual agreement (Hulme 2009). The examination of SME business leaders carried out here demonstrates that this is possible and that such leaders could have an important role to play over the next few years.

\section{NOTES}

${ }^{1}$ SMEs are defined as "enterprises which employ fewer than 250 persons and which have an annual turnover not exceeding EUR 50 million, and/or an annual balance sheet total not exceeding EUR 43 million"' (EU Commission 2003: 39).

${ }^{2}$ 'Innovation-Support-Organizations' are seen as intermediaries who are crucial for the development and innovation of businesses and can be especially designed to communicate climate change knowledge "or organizations which perform this function in addition to other activities" (Kaufmann \& Tödtling 2001: 801).

${ }^{3}$ According to the EU Commission (2003: 39) "an enterprise which employs fewer than 10 persons and whose annual turnover and/or annual balance sheet total does not exceed EUR 2 million" is defined as a microenterprise.

\section{ACKNOWLEDGEMENTS}

This work was supported by the European Union through the European Social Fund. We acknowledge with thanks the participating Cornish businesses and all other study participants, especially Business Leaders for Low Carbon, Cornwall Council, and Cornwall Sustainable Tourism Project. The authors would also like to thank Professor Catherine Leyshon, Dr. Kirsten Abernethy, and Philipp Grunewald for early discussions leading to the publication of this manuscript.

\section{REFERENCES}

Aragón-Correa JA, Matias-Reche F \& Senise-Barrio ME 2004. Managerial discretion and corporate commitment to the natural environment. Journal of Business Research 57: 9, 964-975. http://dx. doi.org/10.1016/s0148-2963(02)00500-3 .

Bandura A 1977. Self efficacy: towards a unifying theory of behavioural change. Psychological Review 84: 2, 191-215.

http://dx.doi.org/10.1037//0033-295x.84.2.191.

Battisti M \& Perry M 2011. Walking the talk? Environmental responsibility from the perspective of small-business owners. Corporate Social Responsibility and Environmental Management 18: 3, 172-85. http://dx.doi.org/10.1002/csr.266.

BBC 2013. PM. Coverage and analysis of the day's news. BBC Radio 4. <http://www.bbc.co.uk/programmes/b039q5fc> 13.09.2013.

BIS (Department for Business, Innovation and Skills) 2013. Statistical Release. Business population estimates for the UK and regions 2013. BIS, London.

Boykoff M, Goodman M \& Curtis I 2009. Cultural politics of climate change: interactions in the spaces of the everyday, environment, politics and development. Working Paper Series. Department of Geography, King's College, London.

Broome J 2012. Climate matters: ethics in a warming world. W.W. Norton \& Company, London.

Brundtland GH 1987. Our common future. Report of the world commission on environment and development. To the General Assembly as an annex to document A/42/427, Development and International Co-Operation, Environment. United Nations, New York.

Carbon Neutral 2013. SMEs can quickly achieve business benefits from carbon management, The CarbonNeutral Company. <http://www.carbonneutral.com/knowledge-centre/company-blog/ smes-can-quickly-achieve-business-benefits-fromcarbon management/> 22.09.2013.

Carroll AB 1991. The pyramid of corporate social responsibility: toward the moral management of organizational stakeholders. Business Horizons 34: 4, 39-48. http://dx.doi.org/10.1016/0007-6813(91)90005-g.

Carter N 2007. The politics of the environment: ideas, activism, policy. Cambridge University Press, Cambridge.

Cassells S \& Lewis K 2011. SMEs and environmental responsibility: do actions reflect attitudes? Corp. Soc. Responsible and Environmental Management 18: 3, 186-199. http://dx.doi.org/10.1002/ csr.269.

Christensen CM, Baumann H, Ruggles R \& Sadtler TM 2006. Disruptive innovation for social change. Harvard Business Review 84: 12, 94-101.

Cook J, Nuccitelli D, Green SA, Richardson M, Winkler B, Painting R, Way R, Jacobs P \& Skuce A 2013. Quantifying the consensus on anthropogenic global warming in the scientific literature. Environmental Research Letters 8: 2, 1-7. http:// dx.doi.org/10.1088/1748-9326/8/2/024024.

Corner A, Markowitz E \& Pidgeon N 2014. Public engagement with climate change: the role of human values. WIREs Climate Change 5: 3, 411 422. http://dx.doi.org/10.1002/wcc.269.

Cornwall Council 2011. Connecting Cornwall: 2030. Moving towards a green peninsula. Evidence Base. Cornwall Council, Truro.

Cornwall Council 2013. Cornwall and Isles of Scilly LEP looks forward to next round of European funding. Cornwall Council. <http://www.cornwall.gov. uk/default.aspx?Page=34230> 15.02.2014. 
Crang MA \& Cook I 2009. Doing ethnographies. Sage, London.

Curtis K \& Schneider A 2001. Understanding the demographic implications of climate change, estimates of localized population predictions under future scenarios of sea-level Rise. Population and Environment 33: 1, 28-54. http://dx.doi.org/10.1007/s11111-011-0136-2.

Dowling R 2010. Power, subjectivity, and ethics in qualitative research. In Hay I (ed). Qualitative Research Methods in Human Geography, 26-39. Oxford University Press, Oxford.

Dunphy DC, Griffiths AB \& Benn SH 2007. Organizational change for corporate sustainability. Routledge, London.

Eco-Monitor 2013. UK SMEs can save $£ 400$ million a year through carbon footprint reduction and certification. Eco-Monitor. <http://www.ecomonitor. com/uk-smes-can-save-400-million-a-yearthrough-carbon-footprint-reduction-and-certification/> 17.02.2014.

Eisenhardt KM 1989. Building theories from case study research. Academy of Management Review 14: 4, 532-550.

Enkvist PA \& Vanthournout H 2008. How companies think about climate change. McKinsey Quarterly 2: 46-51.

EU Commission 2003. Commission Recommendation 2003/361/EC of 6 May 2003 concerning the definition of micro, small and medium-sized enterprises. Official Journal L 124 of 20.05.2003.

Fish R 2009. Minimal futures: narrating space-time determinacy in the public policy domain. Working paper. Omni Consulting, Davis, CA.

Gallopín GC 2006. Linkages between vulnerability, resilience, and adaptive capacity. Global Environmental Change 16: 3, 293-303. http://dx.doi. org/10.1016/j.gloenvcha.2006.02.004.

Brace C \& Geoghegan H 2011. On climate change and cultural geography: farming on the Lizard Peninsula, Cornwall, UK. Climatic Change 113: 1, 55-66. http://dx.doi.org/10.1007/s10584-0120417-5.

Glass JM 1993. Shattered Selves: multiple personality in a Postmodern World. Cornell University Press, Ithaca.

Global Compact 2010. Global Compact - International Yearbook 2010. Macondo Media Group, Muenster.

Goodall AH 2008. Why Have the Leading Journals in Management (and Other Social Sciences) Failed to Respond to Climate Change? Journal of Management Inquiry 17: 4, 408-420. http://dx.doi. org/10.1177/1056492607311930.

Hart S 2007. Capitalism at the crossroads. Aligning business, earth, and humanity. Pearson Education, New Jersey.

Hekman S 1999. Feminism, identity and difference. Frank Cass Publishers, Ilford.
Hillary (ed.) R 2004. Environmental management systems and the smaller enterprise. Journal of Cleaner Production 12: 6, 561-569. http://dx.doi.org/10.1016/j.jclepro.2003.08.006.

Hoffman A 2004. Climate change strategy, the business logic behind voluntary greenhouse gas reductions. Working Paper No. 905. University of Michigan, Michigan.

Hoffman A 2006. Getting ahead of the curve: Corporate Strategies that address climate change. The Pew Centre On Global Climate Change, Arlington.

Hoffman A 2010. Climate change as a cultural and behavioural issue: Addressing barriers and implementing solutions. Organizational Dynamics 39: 4, 295-305.

http://dx.doi.org/10.1016/j.orgdyn.2010.07.005.

Hoffman A 2012. Climate science as culture war. Stanford Social Innovation Review 10: 4, 30-37.

Hoffman A \& Jennings P 2012. The social and psychological foundations of climate change. Solutions 4: 3, 58-65. http://www.thesolutionsjournal. com/node/1130.

Houghton J 2009. Global Warming. The Complete Briefing. Cambridge University Press, Cambridge.

Hulme M 2009. Why we disagree about climate change. Understanding controversy, inaction and opportunity. Cambridge University Press, Cambridge.

Hulme M 2011. Meet the humanities. Nature Climate Change 1: 4, 177-179. http://dx.doi.org/10.1038/ nclimate1150.

Hulme M, Dessai S, Lorenzoni I \& Nelson DR 2009. Unstable climates: exploring the statistical and social constructions of normal science. Geoforum 40: 2, 197-206. http://dx.doi.org/10.1016/j.geoforum.2008.09.010.

IPCC 2007. Climate Change 2007: Synthesis Report. Cambridge University Press, Cambridge, United Kingdom and New York, NY, USA.

IPCC 2013. Climate Change 2013: The Physical Science Basis. Contribution of Working Group I to the Fifth Assessment Report of the Intergovernmental Panel on Climate Change. Cambridge University Press, Cambridge, United Kingdom and New York, NY, USA.

Jackson T 2009. Industrial ecology in Europe beyond the growth economy. Journal of Industrial Ecology 13: 4, 487-490. http://dx.doi.org/10.1111/j.1530-9290.2009.00151.x.

Jenkins H 2006. Small business champions for corporate social responsibility. Journal of Business Ethics 67: 3, 241-256. http://dx.doi.org/10.1007/s10551006-9182-6.

Kaufmann A \& Tödtling F 2001. Science-industry interaction in the process of innovation: the importance of boundary-crossing between systems. Research Policy 30: 5, 791-804. http://dx.doi.org/10.1016/s0048-7333(00)00118-9. 
Kerr IR 2006. Leadership strategies for sustainable SME operation. Business Strategy and the Environment 15: 1, 30-39.

http://dx.doi.org/10.1002/bse.451.

Kollmuss A \& Agyeman J 2002. Mind the gap: Why do people act environmentally and what are the barriers to pro-environmental behavior? Environmental Education Research 8: 3, 239-260. http:// dx.doi.org/10.1080/13504620220145401.

Koomey JG 2012. Cold cash, cool climate: Sciencebased advice for ecological entrepreneurs. Analytics Press, Burlingame, CA.

Kotter JP 2001. What leaders really do. Harvard Business Review 79: 11, 85-96.

Lewontin RC 1992. Biology as ideology: the doctrine of DNA. Harperperennial, New York.

Leyson C \& Geoghegan H 2012. Human geographies of climate change, landscape, temporality, and lay knowledges. Progress in Human Geography 35: 3, 284-302.

http://dx.doi.org/10.1177/0309132510376259.

Loew T, Ankele K, Braun S \& Clausen C 2004. Significance of the CSR debate for sustainability and the requirements for companies. Institute For Ecological Economy Research Hmbh IOW, Berlin.

Moir E \& Leyshon M 2013. The design of decisionmaking: Participatory budgeting and the production of localism. Local Environment 18: 9, 1002-1023. http://dx.doi.org/10.1080/13549839 .2012 .752798 .

Murphy JM, Sexton DMH, Jenkins GJ, Booth BBB, Brown CC, Clark RT, Collins M, Harris GR, Kendon EJ, Betts RA, Brown SJ, Humphrey KA, McCarthy MP, McDonald RE, Stephens A, Wallace C, Warren R, Wilby R \& Wood RA 2009. UK climate projections science report: Climate change projections. Met Office Hadley Centre, Exeter.

Nerlich B, Koteyko N \& Brown B 2010. Theory and language of climate change communication. WIREs Climate Change 1: 1, 97-110. http://dx. doi.org/10.1002/wcc.2.

Norgaard KM 2006. We don't really want to know; environmental justice and socially organized denial of global warming in Norway. Organization and Environment 19: 3, 347-370. http://dx.doi. org/10.1177/1086026606292571.

Norgaard KM 2003. Denial, privilege and global environmental justice, the case of climate change. Centre for Development and the Environment, Oslo.

O'Neill SJ \& Hulme M 2009. An iconic approach for representing climate change. Global Environmental Change 19: 4, 402-410.

http://dx.doi.org/10.1016/j.gloenvcha.2009.07.004.

Office of National Statistics 2012. Regional Statistics. Office of National Statistics (2012). <http:// www.statistics.gov.uk/hub/regional-statistics/ index.html> 02.02.2013.

Reinhardt F \& O'Neill Packard KO 2001. A business managers' approach to climate change. In Claussen E, Cochran VA \& Davis DP (eds). Cli- mate change, science, strategies, and solutions, 269-279. Brill Academic Publishers, Leiden.

Parker CM, Redmond J \& Simpson M 2009. A review of interventions to encourage SMEs to make environmental improvements. Environment and Planning C 27: 2, 279-301. http:// dx.doi.org/10.1068/c0859b.

Patenaude G 2011. Climate change diffusion: while the world tips, business schools lag. Global Environmental Change 21: 1, 259-271. http://dx.doi.org/10.1016/j.gloenvcha.2010.07.010.

Porter ME \& Kramer MR 2006. Strategy and society. The link between competitive advantage and corporate social responsibility. Harvard Business Review 84: 12, 78-92.

Porter ME \& Kramer MR 2011. The big idea. Creating shared value. How to reinvent capitalism - and unleash a wave of innovation and growth. Harvard Business Review 89, 1, 1-17.

Porter ME \& Reinhardt FL 2007. Grist: a strategic approach to climate. Forethought. Harvard Business Review 85: 10, 22-26.

Rajgor G \& Malachowsk L 2005. Climate Change. How UK businesses can benefit by reducing carbon emissions. Director Publications Ltd, London.

Revell A \& Blackburn R 2007. The business case for sustainability? An examination of small firms in the UKs construction and restaurant sectors. Business Strategy and the Environment 16: 6, 404-420. http://dx.doi.org/10.1002/bse.499.

Rogan R, O'Connor M \& Horwitz P 2005. Nowhere to hide: awareness and perceptions of environmental change, and their influence on relationships with place. Journal of Environmental Psychology 25: 2, 147-158. http://dx.doi.org/10.1016/j.jenvp.2005.03.001.

Rorty R 1989. Contingency, irony and solidarity. Cambridge University Press, Cambridge.

Sangmeister H 2009. Entwicklungszusammenarbeit Im 21. Jahrhundert. Ein Überblick (In German). Nomos, Baden-Baden.

Sarewitz D \& Pielke RA Jr 2000. Breaking the global warming gridlock. [Electronic version]. The Atlantic Monthly, July, 54-64.

Stern N 2006. The economics of climate change: the Stern review. Cambridge University Press, Cambridge.

SQW 2012. Cornwall and Isles of Scilly LEP: Strategy and business plan evidence base papers: 1 - Headline Economic Indicators. SQW, London.

Tilley F 1999. The gap between the environmental attitudes and the environmental behaviour of small firms. Business Strategy and the Environment 8: 4 238-248.

UKCP 2009. UK climate projections user interface. UKCP09. <http://ukclimateprojections-ui.metoffice. gov.uk/ui/admin/login.php> 18.02.2014.

Vernon J, Essex S, Pinder D \& Curry K 2003. The greening of tourism micro-businesses: outcomes of focus group investigations in South East Corn- 
wall. Business Strategy and the Environment 12: 1, 49-69. http://dx.doi.org/10.1002/bse.348.

Visser W \& Adey M 2007. Policy dialogue on sustainability: a new model - the case of the corporate leaders group on climate change. Cambridge Programme for Sustainability Leadership Paper Series 3. Cambridge University, Cambridge.

Visser W \& Crane A 2010. Corporate sustainability and the individual: Understanding what drives sustainability professionals as change agents. $<$ http://ssrn.com/abstract $=1559087>$ 17.02.2014.

Vives A 2006. Social and environmental responsibility in small and medium enterprises in Latin America. The Journal of Corporate Citizenship 2006: 21, 39-50. http://dx.doi.org/10.9774/gleaf.4700.2006.sp.00006.

Williams S \& Schaefer A 2013. Small and medium sized enterprises and sustainability: managers' values and engagement with environmental and climate change issues. Business Strategy and the Environment 22:3, 173-186. http://dx.doi.org/10.1002/ bse. 1740 .

Wilson CDH, Williams ID \& Kemp S 2012. An evaluation of the impact and effectiveness of environ- mental legislation in small and medium-sized enterprises: experiences from the UK. Business Strategy and the Environment 21: 3 141-156. http:// dx.doi.org/10.1002/bse.720.

Wilson TD 1997. Information behaviour: an interdisciplinary perspective. Information Processing \& Management 33: 4, 551-572. http://dx.doi.org/10.1016/s0306-4573(97)00028-9.

Winchester HPM \& Rofe MW 2010. Qualitative research and its place in human geography. In Hay I (ed). Qualitative research methods in human geography, 1-25. Oxford University Press, Oxford.

Wittgenstein L 1958. Philosophical investigations. Basil Blackwell, Oxford.

Whitmarsh L, Seyfang G \& O'Neill S 2011. Public engagement with carbon and climate change: to what extent is the public 'carbon capable'? Global Environmental Change 21: 1, 56-65. http://dx. doi.org/10.1016/j.gloenvcha.2010.07.011.

Wolf J \& Moser SC 2011. Individual understandings, perceptions, and engagement with climate change: insights from in-depth studies across the world. Wiley Interdisciplinary Reviews - Climate Change 2: 4, 547-569. http://dx.doi.org/10.1002/ wcc. 120 . 